\section{Sacroileitis y enfermedad de Behçet}

\section{Sr Director:}

Se ha sugerido en diversas ocasiones que la Enfermedad de Behçet (EB) formase parte del grupo de las espondiloartropatías seronegativas. Existen estudios donde se objetiva la existencia de sacroileitis en pacientes diagnosticados de EB, junto a la coexistencia de la positividad de los antígenos HLA-B51 y HLA-B27. Añadimos un caso más a la literatura destacando la existencia de una sacroileitis bilateral en una paciente con EB con exploración anodina y radiografía normal.

Se trata de una mujer de 27 años, fumadora de 6 cig/día y diagnosticada de EB desde hacía dos años en base a una clínica ocular (uveitis anterior) y mucocutánea (pseudofoliculitis cutánea y aftas bucogenitales). No había presentado complicaciones y seguía tratamiento con prednisona ( $15 \mathrm{mg} /$ día), pentoxifilina, talidomida y anticonceptivos orales. Refiere cuadro de una semana de dolor en cara posterior de muslo derecho progresivo y agudizado con los movimientos incapacitando la deambulación. Asimismo refiere dolor en hombro izquierdo autolimitado, sin signos inflamatorios, una semana antes. Niega antecedente traumático anterior o clínica similar previamente. Se acompaña de la aparición de pápulas-pústulas generalizadas de predominio en extremidades, junto a hiperemia conjuntival y aftas bucogenitales dolorosas. En los últimos días febrícula vespertina y síndrome general. Niega clínica digestiva. A la exploración se encuentra afectada por el dolor. Foliculitis palpebral bilateral con exploración de polo anterior normal. Afta en mucosa yugal derecha. No adenopatías cervicales. Auscultación cardiopulmonar normal. Abdomen sin masas o megalias, no doloroso. Lasegue -.Fabere derecho dudoso. Extremidades con papulopústulas, sin edemas, cordón venoso o signos de flogosis.

En analítica destaca un aumento de parámetros inflamatorios (PCR: 4,1 mg/dl) con leve leucocitosis y anemia normocítica Resto de bioquímica completa normal. Las determinaciones del HLA-B27 y HLA-B51 resultaron negativas. Radiografías de tórax, columna lumbar, pelvis y caderas sin hallazgos significativos. TC pelvis con afectación de ambas sacroiliacas, predominantemente derecha, con esclerosis subcondral y discretos signos de erosión (Fig. 1). Gammagafía ósea: En la fase precoz vascular, aumento de captación con hiperemia en ambas sacroilíacas. En la fase tardía, ósea, aumento de la captación del trazador en sacroiliacas, de predominio en la derecha. Moderado aumento de captación de la articulación esternocostoclavicular izquierda compatible con artropatía inflamatoria.

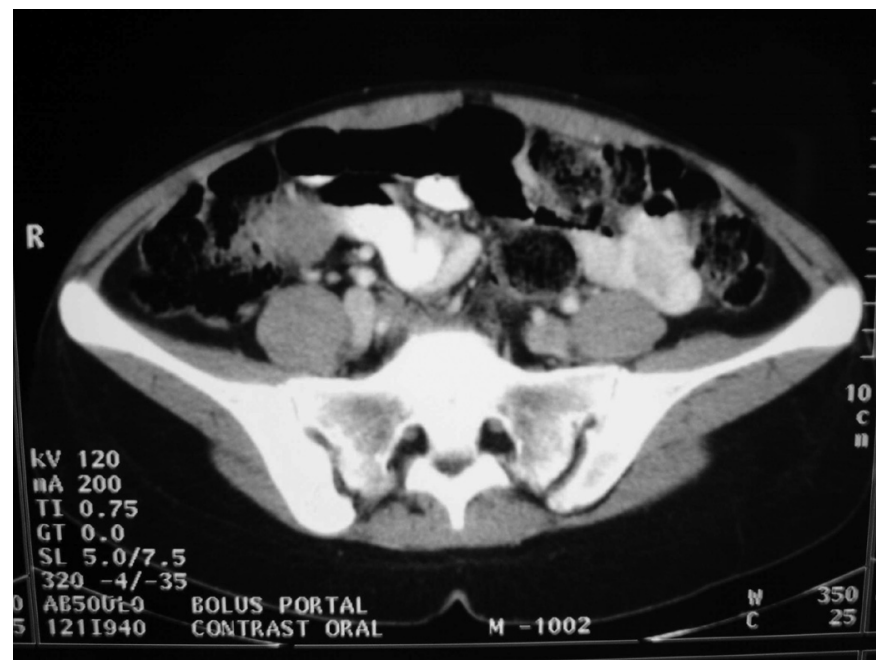

Fig. 1.
La afectación articular en la EB ocurre hasta en un 50\% y suele ser oligoarticular, no erosiva y de predominio en miembros inferiores. Afecta a grandes articulaciones, sobretodo a rodillas, tobillos y codos presentando un curso subagudo, intermitente y no deformante. Las articulaciones sacroiliacas no suelen afectarse por lo que no se considera la EB dentro de las espondiloartropatías. Varios autores han descrito el hallazgo frecuente de sacroileitis en la EB, dependiendo en gran medida del grado de afectación y de la técnica de imagen utilizada (1-4). Existen a su vez trabajos que no objetivan una clara relación comparando con la población general $(5,6)$. Aunque sea más frecuente la forma oligoarticular que la sacroiliaca, el hallazgo de sacroileitis en la EB hace que sea necesario realizar un diagnóstico diferencial con las espondiloartropatías seronegativas (7). Otro punto importante a destacar, a propósito de nuestro caso, es la necesidad de utilizar técnicas de imagen apropiadas, ya que en grados leves-moderados en donde la exploración y la radiografía simple pueden ser normales, es necesario la utilización de la TC o la RMN para el diagnóstico (8-10).

\section{M. Arias, M. Ramos-Casals 1 , G. Espinosa ${ }^{1}$, R. Reyes $^{2}$}

Servicio de Medicina Interna. Hospital de Cabueñes. Gijón. ${ }^{1}$ Servicio de Enfermedades Autoinmunes Sistémicas. ${ }^{2}$ Servicio de Reumatología. Hospital Clínico. Barcelona

1. Olivieri I, Gemignani G, Pecori F, Semeria R, Pasero G. Coexisting ankylosing spondylitis and Behçet's syndrome: a report of six cases. In: O'Duffy JD, Kokmen E, editors, Behçet's Disease: Basic and Clinical Aspects. New York: Marcel Dekker, 1991: 247-52.

2. Moll JMH, Haslock I, Macrae IF, Wright V. Associations between ankylosing spondylitis, psoriatic arthritis, Reiter's disease, the intestinal arthropathies, and Behçet's syndrome. Medicine (Baltimore) 1974; 53: 343-64.

3. Sakane T, Takeno M, Suzuki N, Inaba G. Behcet's disease. N Engl J Med 1999; 341: 1284-91.

4. Cheng YK, Thong BY, Chng HH. Behcet's disease: experience in a tertiary rheumatology centre in Singapore and a review of the literature. Ann Acad Med Singapore 2004; 33: 510-4.

5. Chamberlain MA, Robertson RJ. A controlled study of sacroiliitis in Behcet's disease. Br J Rheumatol 1993; 32: 693-8.

6. Hyun Kyu Chang, Deok Hee Lee, Seung Mun Jung, Soo Jung Choi, Jeong Uk Kim, Young Joon Choi, et al. The Comparison Between Behcet's Disease and Spondyloarthritides: Does Behcet's Disease Belong to the Spondyloarthropathy Complex? J Korean Med Sci 2002; 17: 524-9.

7. Grana Gil J, Sánchez Meizoso MO. Criterios diagnósticos y diagnóstico diferencial de la enfermedad de Behçet. Rev Clin Esp 2002; 202: 20-2.

8. Olivieri I, Gemignani G, Camerini E, Semeria R, Pasero G. Computed tomography of the sacroiliac joints in four patients with Behçet's syndrome confirmation of sacroileitis. Br J Rheumatol 1990; 29: 264-7.

9. Collantes Estévez E, Muñoz Gomariz E. Estrategias diagnósticas en las espondiloartropatias. Rev Clin Esp 2005; 205: 27-9.

10. Maghraoui AE, Tabache F, Bezza A, Abouzahir A, Ghafir D, Ohayon $\mathrm{V}$, et al. A controlled study of sacroiliitis in Behcet's disease. Clin Rheumatol 2001;20:189-91.

\section{Misión del internista en el hospital moderno}

\section{Sr. Director:}

El editorial publicado recientemente en su revista (1), que expone con acertada sistematización cual es la misión e influencia de la Medicina Interna en el conjunto del hospital, transmite al lector una visión de la especialidad con la que, en general, nin- 